\title{
Histology and molecular biology studies on the expression and localization of angiopoietin-like protein 8 in human tissues
}

\author{
NAOHIKO AKIMOTO $^{1,2}$, RYUICHI WADA $^{1,3}$, KATSUHIKO IWAKIRI $^{2}$ and ZENYA NAITO ${ }^{1,3}$ \\ Departments of ${ }^{1}$ Integrated Diagnostic Pathology and ${ }^{2}$ Gastroenterology, Nippon Medical School; \\ ${ }^{3}$ Department of Pathology, Nippon Medical School Hospital, Tokyo 113-8602, Japan
}

Received February 11, 2019; Accepted September 18, 2019

DOI: $10.3892 /$ br.2019.1243

\begin{abstract}
Angiopoietin-like protein (ANGPTL) 8 regulates the partitioning of triglycerides by inhibiting lipoprotein lipase in muscle and adipose tissues. ANGPTL8 is expressed in the liver and adipose tissue and secreted into the blood. However, the precise localization of ANGPTL8-expressing cells in these tissues remains unknown. The aim of the present study was to investigate the localization of ANGPTL8-expressing cells in human tissues. Using formalin-fixed paraffin-embedded human tissue specimens, the expression of ANGPTL8 was investigated by reverse transcription-quantitative polymerase chain reaction (RT-qPCR), immunohistochemistry (IHC) and in situ hybridization (ISH). The expression level of ANGPTL8 mRNA was the highest in the liver, followed by lipoma, hibernoma and normal adipose tissue. In the liver, wild type (KF809856) and two splice variants of ANGPTL8 mRNA (KF809857 and KF809858) were found to be expressed. The expression level of the splice variant KF809858, which produces a short form of ANGPTL8, accounted for $<1 \%$ of ANGPTL8 in the liver. IHC revealed that ANGPTL8 was expressed in hepatocytes in zone 1 of the hepatic acinus in the liver. In the adipose tissue, mature adipocytes weakly expressed ANGPTL8, while immature adipocytes strongly expressed it. ISH confirmed ANGPTL8 mRNA expression in portal hepatocytes and immature adipocytes. ANGPTL8 was expressed in the cells, which actively uptake and metabolize triglycerides. In hibernoma, the ANGPTL8 protein and mRNA were homogeneously expressed in tumor cells. The expression of ANGPTL8 was associated with the differentiation state and
\end{abstract}

Correspondence to: Dr Ryuichi Wada, Department of Integrated Diagnostic Pathology, Nippon Medical School, 1-1-5 Sendagi, Bunkyo-ku, Tokyo 113-8602, Japan

E-mail: w-ryuichi@nms.ac.jp

Abbreviations: ANGPTL8, angiopoietin-like protein 8; IHC, immunohistochemistry; ISH, in situ hybridization; LPL, lipoprotein lipase; SNP, single nucleotide polymorphism

Key words: angiopoietin-like protein 8, liver, adipose tissue, partitioning, differentiation, metabolism, immunohistochemistry, in situ hybridization activity of lipid metabolism in a subpopulation of cells in the liver and adipose tissue. The association may be helpful for the understanding of local metabolic state in organs and diseases associated with the lipid metabolism.

\section{Introduction}

Angiopoietin-like protein (ANGPTL) 8 is a member of the ANGPTL family (1) and is also known as RIFL (2), TD26 (3), lipasin (4), PRO1185, PVPA599, C19orf80 and betatrophin (5). ANGPTL8 is involved in the partitioning of triglycerides to muscle and adipose tissues in conjunction with ANGPTL3 and ANGPTL4 (6,7). They regulate the activity of lipoprotein lipase (LPL) in organs (7). ANGPTL8 interacts with ANGPTL3 and inhibits LPL in muscle tissue, whereas ANGPTL4 inhibits LPL in adipose tissue.

The ANGPTL8 gene is located on chromosome 19 and consists of four exons that encode 198 amino acids. The protein contains a signal peptide consisting of 20 amino acids at the N-terminus, the specific epitope 1 domain and two coiled coil domains (Fig. 1A). Specific epitope 1 domain is necessary for inhibition of LPL, and two coiled coil domains are necessary for the complex formation with ANGPTL3 and ANGPTL4 (6,7). The protein is processed to the mature protein by cleavage of signal peptide and released into the bloodstream (1).

It was reported that ANGPTL8 is highly expressed in the liver, white and brown adipose tissue (BAT) $(2,5,6)$. In vitro studies demonstrated that the expression level of ANGPTL8 is altered depending on the differentiation and functional state of the cells (2). However, the precise localization and distribution of ANGPTL8-expressing cells in these organs remains unclear. The elucidation of the localization of ANGPTL8 in these organs will contribute to the understanding of the physiological roles of ANGPTL8 and the association with local lipid metabolism. Further, this may aid the understanding of the pathological role of ANGPTL8 in metabolic diseases and the development of novel therapies for these diseases.

The aim of the present study was to investigate the expression and localization of ANGPTL8 in normal human tissues. Using formalin-fixed paraffin-embedded (FFPE) specimens, ANGPTL8 expression levels and localization were examined by molecular biological methods. During the cloning of ANGPTL8 mRNA from normal liver, splice variants were 
identified. The structures of the splice variants were also documented.

\section{Materials and methods}

Sequencing of ANGPTL8 mRNA from the liver. The coding sequence of ANGPTL8 was amplified and cloned from the total RNA of the liver (cat. no. K4000-1; lot no. 0111320; Thermo Fisher Scientific, Inc.). Total RNA $(2 \mu \mathrm{g})$ was treated with DNase I (Thermo Fisher Scientific, Inc.) at room temperature (RT) for $15 \mathrm{~min}$, and cDNA was synthesized by random primer method using the SuperScript III First Strand Synthesis kit (Thermo Fisher Scientific, Inc.) according to the manufacturer's instructions. PCR was performed with cDNA transcribed from 100 ng total RNA using the AmpliTaq Gold PCR kit (Thermo Fisher Scientific, Inc.). The primers used were: Forward (F), 5'-TAGGCGCCCCCATGGGCGGCC CAGA-3' and reverse (R), 5'-GGCTGGGAGCGCCGCTGT GT-3' (Fig. 1A). The thermocycling conditions were as follows: $95^{\circ} \mathrm{C}$ for $10 \mathrm{~min}$, followed by 40 cycles of $95^{\circ} \mathrm{C}$ for $1 \mathrm{~min}, 55^{\circ} \mathrm{C}$ for $1 \mathrm{~min}$ and $72^{\circ} \mathrm{C}$ for $1 \mathrm{~min}$. The amplified PCR product was cloned into pCR-II TOPO (Thermo Fisher Scientific, Inc.) using the TA-cloning method. Cloned ANGPTL8 fragments were sequenced using the BigDye Terminator v3.1 Cycle Sequencing kit (Thermo Fisher Scientific, Inc.).

Human tissue samples and histological assessment. FFPE specimens of lipoma, hibernoma and normal human tissues of the liver, adipose tissue, heart, stomach, small intestine, large intestine, pancreas, spleen, kidney, lymph node, bone marrow, thyroid, adrenal gland, ovary and testis were used in the present study. The normal human tissues were collected adjacent to malignant tumor tissues in resected organs. Lipomas and hibernomas were resected tumor tissues. The tissues were fixed in 10\% formalin at RT for $24 \mathrm{~h}$ and embedded in paraffin. Three specimens of each normal tissue, lipoma and hibernoma were used for the study. Tissues were obtained from the archives of pathological specimens of Nippon Medical School Hospital (Tokyo, Japan) and were originally obtained between January 2014 and December 2018. The tissues obtained from 45 cases; median age, 65 (25-81) years. A total of 21 male and 24 female patients were recruited. The personal data were anonymized and only pathological diagnoses were available for the study. This study was performed in accordance with the principles of the Declaration of Helsinki, 2013 and the Japanese Society of Pathology, Ethics Committee. The study was approved by Ethics Committee of Nippon Medical School Hospital (approval no. 30-11-1304). Written informed consent was obtained from all patients at the time of hospitalization.

FFPE specimens of lipoma, hibernoma and normal human tissues were stained with hematoxylin and eosin. Briefly, $4-\mu \mathrm{m}$-thick sections were stained with hematoxylin for $5 \mathrm{~min}$ and eosin for $3 \mathrm{~min}$ at room temperature. The stained sections were observed using a light microscope (magnifications, x100, x200 and x400).

RNA extraction. Total RNA was extracted from FFPE specimens using the RNeasy FFPE kit (Qiagen, Inc.) according to the manufacturer's instructions. Briefly, five paraffin sections $(4 \mu \mathrm{m})$ of a FFPE specimen were deparaffinized in $1.5-\mathrm{ml}$ tubes. After the sections were dried, they were digested in PKD buffer with proteinase $\mathrm{K}$ at $56^{\circ} \mathrm{C}$ until the tissues were completely dissolved. Total RNA was extracted, and the concentration was measured.

Reverse transcription-quantitative (RT-q)PCR of wild type ANGPTL8. The wild type ANGPTL8 mRNA (KF809856) was quantitated in the normal human tissues, lipoma and hibernoma. Total RNA (200 ng) were extracted from FFPE specimens and were treated with DNase I (Thermo Fisher Scientific, Inc.) at RT for 15 min. cDNA was synthesized using the SuperScript VILO cDNA Synthesis kit (Thermo Fisher Scientific, Inc.) according to the manufacturer's instructions. The primers for wild type ANGPTL8 mRNA were: F1, 5'-CAG GAACAGCCTGGGTCTCTA-3' and R1, 5'-AGCTGCAGA ATATCCTCCTCCAT-3' (Fig. 1A). For standardization, the expression level of $18 \mathrm{~S}$ rRNA was quantified using the following primers: Forward, 5'-TAGCCTTTGCCATCACTGCC-3' and reverse, 5'-CACCACAACTCCTTTCGTCTGTAA-3'. The qPCR was performed in $20 \mu \mathrm{l}$ reaction solution containing $1 \mathrm{X}$ PowerUp SYBR Green Master mix (Thermo Fisher Scientific, Inc.), $500 \mathrm{nM}$ forward and reverse primers and cDNA transcribed from $100 \mathrm{ng}$ total RNA as the template. The reaction was initiated at $50^{\circ} \mathrm{C}$ for $2 \mathrm{~min}$ and $95^{\circ} \mathrm{C}$ for $2 \mathrm{~min}$, followed by 40 cycles of sequential incubations at $95^{\circ} \mathrm{C}$ for $3 \mathrm{sec}$ and $60^{\circ} \mathrm{C}$ for $30 \mathrm{sec}$. The changes in fluorescence were monitored using a StepOne Plus Real-Time PCR system (Thermo Fisher Scientific, Inc.) and quantitation cycles (Cq) were determined. The expression level of wild type ANGPTL8 in the tissues was calculated as follows: $\Delta \mathrm{Cq}=\mathrm{Cq}$ (wild type)-Cq(18S rRNA); and $\Delta \Delta \mathrm{Cq}=\Delta \mathrm{Cq}$ (tissue) $-\Delta \mathrm{Cq}$ (liver). Expression levels were calculated following the $2^{-\Delta \Delta \mathrm{Cq}}$ method (8).

Expression ratio of splice variant 2/wild type ANGPTL8. The splice variant 2 of ANGPTL8 (KF809858) was quantified in liver, adipose tissue and hibernoma. The splice variant 2 was quantified using $\mathrm{F} 1$ and R2 primers (R2, 5'-TGTGGC TCTGCTTGTCA-3'; Fig. 1A). RT-qPCR was performed as detailed in the previous section. The expression ratio of splice variant 2/wild type ANGPTL8 was determined as follows: $\Delta \mathrm{Cq}=\mathrm{Cq}$ (splice variant 2$)-\mathrm{Cq}$ (wild type). The expression ratio was obtained using the $2^{-\mathrm{ACq}}$.

Immunohistochemistry (IHC). IHC was performed on FFPE sections of normal human tissues, lipoma and hibernoma. Paraffin sections $(4 \mu \mathrm{m})$ were deparaffinized in xylene and ethanol and hydrated in PBS. Sections were then treated with $10 \mathrm{mM}$ citrate buffer (pH 6.0) at $121^{\circ} \mathrm{C}$ for $15 \mathrm{~min}$. Endogenous peroxidase activity was blocked with $0.3 \%$ hydrogen peroxide in methanol at RT for 30 min. After incubation with $10 \%$ normal goat serum (Nichirei Biosciences, Inc.) at RT for 30 min, rabbit anti-ANGPTL8 antibody (cat. no. 7619; 1:500; ProSci, Inc.) was applied on the sections. In the negative control without an antibody, PBS was applied to the sections. Sections were incubated at $4^{\circ} \mathrm{C}$ overnight. Subsequently, slides were incubated with a peroxidase-labeled anti-rabbit immunoglobulin antibody using the Histofine Simple Stain MAX-PO (cat. no. 424141; prediluted; Nichirei Biosciences, Inc.) at RT for $1 \mathrm{~h}$. Peroxidase activity was detected by incubation with diaminobenzidine at RT for $2 \mathrm{~min}$ using Histofine DAB 
A

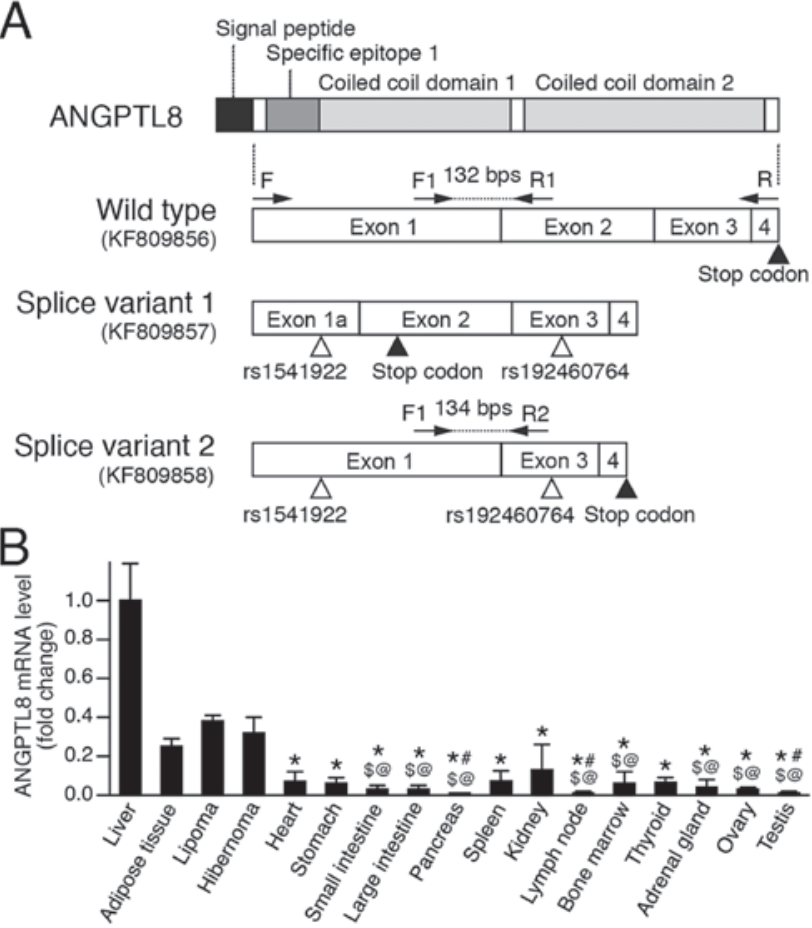

Figure 1. Schematic structure and mRNA expression of ANGPTL8. (A) Schematic structure of the ANGPTL8 protein and gene. ${ }^{\Delta}$ Single nucleotide polymorphisms, rs1541922 in exon 1 and rs192460764 in exon 3; $\mathbf{\Delta}_{\text {stop codon. }}$ (B) mRNA expression of ANGPTL8 in human tissues. " $\mathrm{P}<0.05$ vs. liver; ${ }^{\text {"}} \mathrm{P}<0.05$ vs. adipose tissue; ${ }^{\$} \mathrm{P}<0.05$ vs. lipoma; ${ }^{\circledR} \mathrm{P}<0.05$ vs. hibernoma. ANG$\mathrm{PTL} 8$, angiopoietin-like protein $8 ; \mathrm{F}$, forward primer; $\mathrm{R}$, reverse primer.

Substrate kit (Nichirei Biosciences, Inc.) and the sections were counterstained with hematoxylin at RT for $1 \mathrm{~min}$. The immunostained sections were observed using a light microscope (magnification, x200 and x400).

In situ hybridization (ISH). ISH was performed with an ISH Reagent kit (cat. no. SRK-02; GenoStaff, Co., Ltd.) using FFPE sections $(4 \mu \mathrm{m})$ of normal human tissues, lipoma, and hibernoma. Briefly, sections were deparaffinized, rehydrated in PBS and subsequently incubated in $10 \%$ neutral buffered formalin at RT for $15 \mathrm{~min}$ and treated with $20 \mu \mathrm{g} / \mathrm{ml}$ proteinase $\mathrm{K}$ (cat. no. S3004; Agilent Technologies, Inc.) in Tris- $\mathrm{HCl}(\mathrm{pH}$ 7.6) at $37^{\circ} \mathrm{C}$ for $10 \mathrm{~min}$. After incubation in $10 \%$ neutral buffered formalin at RT for $15 \mathrm{~min}$, samples were incubated in $0.2 \mathrm{~N} \mathrm{HCl}$ at RT for $10 \mathrm{~min}$. G-Hybo hybridization solution (100 $\mu \mathrm{l}$; provided with kit) mixed with a digoxigenin-labeled anti-sense or sense probe was applied to the sections and incubated at $80^{\circ} \mathrm{C}$ for $10 \mathrm{~min}$. The anti-sense and sense probes were synthesized from the wild type ANGPTL8 using the T7/SP6 Digoxigenin Labeling kit (Roche Diagnostics, K.K.) according to the manufacturer's instructions. Following the initial incubation, sections were incubated at $50^{\circ} \mathrm{C}$ overnight and washed twice with $1 \mathrm{X}$ Wash Buffer (provided with kit) at $50^{\circ} \mathrm{C}$ for 10 min. Following blocking with G-Block (provided with kit) at RT for $30 \mathrm{~min}$, sections were further incubated with an alkaline phosphatase-labeled anti-digoxigenin antibody (anti-digoxigenin-AP, Fab fragment; cat. no. 11093274910; 1:1,000; Roche Diagnostics) and the enzymatic activity was detected using nitroblue tetrazolium and 5-bromo-4-chloro-3-indolyl phosphate (NBT/BCIP Stock solution; cat. no. 11681451001; Roche
Diagnostics) according to the manufacturer's instructions. Two types of negative control were used in the present study. In the first type of negative control, the slides were treated with $100 \mu \mathrm{g} / \mathrm{ml}$ RNase A (Takara Bio, Inc.) in 1X standard saline citrate $(150 \mathrm{mM} \mathrm{NaCl} / 15 \mathrm{mM}$ citrate; $\mathrm{pH} 7.0)$ at $37^{\circ} \mathrm{C}$ for $1 \mathrm{~h}$ to remove all endogenous RNA, and in the second type of negative control, the slides were incubated with $100 \mu \mathrm{l}$ G-Hybo without probes at $80^{\circ} \mathrm{C}$ for $10 \mathrm{~min}$. Slides were further processed in the same manner as described. The stained sections were observed using a light microscope (magnification, x200 and x400).

Statistical analysis. Data are expressed as the mean \pm standard deviation of three samples. The statistical analysis was performed using R (version 3.6.1; https://www.r-project.org). The statistical analysis among the organs was conducted using Kruskal Wallis followed by Dunn's post-hoc test. $\mathrm{P}<0.05$ was considered to indicate a statistically significant difference.

\section{Results}

Sequencing of ANGPTL8 $m$ RNA. Amplification and cloning of ANGPTL8 mRNA identified three different fragments in the liver (Fig. 1A). One was KF809856, the wild type mRNA, and KF809857 and KF809858 are two were alternatively spliced mRNAs. The first splice variant (Splice Variant 1; KF809857) lacked 146 base pairs of exon 1. This deletion caused a frame shift producing a truncated protein containing 63 amino acids due to a premature stop codon in exon 2 . The second splice variant (Splice Variant 2; KF809858) lacked 162 base pairs, the entire exon 2, and generated a short version of ANGPTL8. The splice variants contained two single nucleotide polymorphisms (SNPs), rs1541922 and rs192460764 (registered in dbSNP; available at https://www.ncbi.nlm.nih.gov/snp/). The SNP rs192460764 caused the replacement of Arg to Trp (p.Arg172Trp). The wild type ANGPTL8 did not contain these SNPs and no further SNPs were identified.

RT-qPCR of wild type ANGPTL8. The expression level of wild type ANGPTL8 mRNA was determined in the FFPE tissue specimens. Results showed ANGPTL8 levels were highest in the liver, adipose tissue, lipoma and hibernoma (Fig. 1B; Table I); levels in the other tissues were low. The level of ANGPTL8 in the liver was significantly increased compared with the other samples $(\mathrm{P}<0.05)$, except the adipose tissue, lipoma and hibernoma where differences were not significant $(\mathrm{P}>0.05)$. The levels in the adipose tissue, lipoma and hibernoma were also higher than other tissues.

Expression ratio of splice variant 2/wild type ANGPTL8. The level of ANGPTL8 splice variant 2 mRNA, which generates a shorter form of ANGPTL8 due to partial lack of coiled-coiled domains, was quantified in liver, adipose tissue and hibernoma. The level of splice variant 1 , which generates a truncated form of ANGPTL8 and lacks almost entire coiled-coil domains, was not quantitated in the present study. The expression level of the splice variant 2 was below the detection limit in the adipose tissue and hibernoma, and the variant was detected only in the liver. The expression level of the splice variant 2 in the four liver tissues was very low and the relative level was $0.0069 \pm 0.0024$, compared with the wild type ANGPTL8. 
Table I. ANGPTL8 protein and mRNA expression in human tissues.

ANGPTL8 expression

\begin{tabular}{lccc}
\cline { 2 - 4 } Tissue & RT-qPCR (fold-change) & IHC & ISH \\
\hline Liver & $1.00 \pm 0.01$ & + & + \\
Adipose tissue & $0.25 \pm 0.04$ & + & + \\
Lipoma & $0.38 \pm 0.03$ & + & + \\
Hibernoma & $0.32 \pm 0.08$ & + & + \\
Heart & $0.07 \pm 0.05^{\mathrm{a}}$ & - & - \\
Stomach & $0.06 \pm 0.03^{\mathrm{a}}$ & - & - \\
Small intestine & $0.03 \pm 0.02^{\mathrm{a}, c, \mathrm{~d}}$ & - & - \\
Large intestine & $0.03 \pm 0.02^{\mathrm{a}, c, \mathrm{~d}}$ & - & - \\
Pancreas & $0.01 \pm 0.01^{\mathrm{a}-\mathrm{d}}$ & - & - \\
Spleen & $0.06 \pm 0.06^{\mathrm{a}}$ & - & - \\
Kidney & $0.13 \pm 0.13^{\mathrm{a}}$ & - & - \\
Lymph node & $0.01 \pm 0.01^{\mathrm{a}-\mathrm{d}}$ & - & - \\
Bone marrow & $0.06 \pm 0.06^{\mathrm{a}, c, \mathrm{~d}}$ & - & - \\
Thyroid & $0.06 \pm 0.02^{\mathrm{a}}$ & - & - \\
Adrenal gland & $0.04 \pm 0.04^{\mathrm{a}, c, \mathrm{~d}}$ & - & - \\
Ovary & $0.03 \pm 0.01^{\mathrm{a}, \mathrm{c}, \mathrm{d}}$ & - & - \\
Testis & $0.01 \pm 0.01^{\mathrm{a}-\mathrm{d}}$ & - & - \\
\hline
\end{tabular}

${ }^{a} \mathrm{P}<0.05$ vs. liver; ${ }^{\mathrm{b}} \mathrm{P}<0.05$ vs. adipose tissue; ${ }^{\mathrm{c}} \mathrm{P}<0.05$ vs. lipoma; and ${ }^{\mathrm{d}} \mathrm{P}<0.05$ vs. hibernoma. ANGPTL8, angiopoietin-like protein 8 ; IHC, immunohistochemistry; ISH, in situ hybridization; RT-q, reverse transcription-quantitative.

IHC. In the liver, expression of ANGPTL8 was observed in periportal zone 1 of hepatic acinus (Fig. 2A and B). In high magnification, the cytoplasm in the hepatocytes showed a positive reaction (Fig. 2C). The negative control without the primary antibody showed no signal (Fig. 2D). In the adipose tissue, expression of ANGPTL8 was observed in immature adipocytes (Fig. 2E; arrows). The cytoplasmic rims of mature adipocytes in the adipose tissue and lipoma were also stained (Fig. 2E and F). In hibernoma, the foamy cytoplasm of tumor cells was strongly stained (Fig. 2G). The negative control without the primary antibody showed no positive staining (Fig. 2H). Adipose tissue in the bone marrow showed a positive staining (Fig. 2I). The positive staining was not observed in the negative control without primary antibody (Fig. 2J). Positive staining was not observed in the epithelial cells of the small intestine (Fig. 2K), exocrine tissue and the islets of the pancreas (Fig. 2L; arrow heads). Other tissues did not show a positive reaction for ANGPTL8 (data not shown). The results of IHC are summarized in Table I.

ISH. In the liver (Fig. 3A), the cytoplasm of hepatocytes in zone 1 showed a positive signal with the anti-sense probe (Fig. 3B; arrows), whereas no signal was detected with sense probe (Fig. 3C). In the adipose tissue (Fig. 3D), the immature adipocytes showed a strong signal (Fig. 3E; arrowheads), and a weak signal was observed in mature adipocytes (Fig. 3F). In hibernoma (Fig. 3G), the tumor cells showed a positive reaction in the cytoplasm (Fig. $3 \mathrm{H}$ ). No signal was detected in slides hybridized with the sense probe (Fig. 3I). In the section treated with RNase and hybridized with anti-sense probe (Fig. 3J) or in the section hybridized with no probe (Fig. 3K), no signals were detected. In lipoma, a weak signal was observed in mature tumor cells with the anti-sense probe, and other tissues did not show a positive reaction (data not shown). The results of ISH are summarized in Table I.

\section{Discussion}

In the present study, RT-qPCR showed that ANGPTL8 mRNA was expressed in the liver, normal adipose tissue, lipoma and hibernoma. These results are consistent with previous findings, which suggest ANGPTL8 is abundantly expressed in the liver, adipose tissue and BAT $(2,5,6)$. The localization data of ANGPTL8-positive cells by IHC and ISH in these tissues were comparable, suggesting the specific reactivity of the antibody used in the current study. The present study revealed the precise localization of ANGPTL8-expressing cells in the liver and adipose tissue. The expression of ANGPTL8 was homogenous in hibernoma. The distribution of ANGPTL8-expressing cells in the liver and adipose tissue was heterogeneous; there was a difference in the expression levels among the cells in the organs.

In the liver, ANGPTL8 expression was observed in the periportal hepatocytes of the hepatic acinus. The hepatic acinus is separated into three functional zones, and hepatocytes in the periportal zone 1 actively uptake triglycerides and utilize them through $\beta$-oxidation (9). ANGPTL8 is expressed in hepatocytes, which actively metabolize triglycerides under physiological conditions. Increased expression of ANGPTL8 has previously been detected in cultured cells of hepatocellular carcinoma (3). The expression of ANGPTL8 may reflect the metabolic state of carcinoma cells. Serum levels of ANGPTL8 have been shown to correlate with liver steatosis (10) and non-alcoholic fatty liver disease (11). The association of the precise localization of ANGPTL8-expressing hepatocytes with lipid deposition requires to be elucidated.

In adipose tissue, ANGPTL8 was more strongly expressed in immature adipocytes compared with mature adipocytes. This is consistent with previous findings on the expression of ANGPTL8 in preadipocytes, which differentiate into mature adipocytes (2). ANGPTL8 expression may be necessary for the storage of triglycerides. Previous studies reported that the knockdown of ANGPTL8 by siRNA in cultured adipocytes does not affect differentiation, but alters the expression levels of enzymes involved in lipolysis and fatty acid oxidation, resulting in a reduction in triglyceride levels $(2,12)$. Decreases in body weight and fatty tissue have been reported in ANGPTL8 knockout mice (7). The results in the present study further suggested an important role for ANGPTL8 in lipid metabolism by immature adipocytes.

A treatment with an ANGPTL8 antisense oligonucleotide has been reported to promote the uptake and storage of triglycerides in adipose tissue and eventually prevent liver steatosis, and this has been associated with improvements in glucose intolerance in rodents (13). In this situation, immature adipocytes may be a therapeutic target of antisense oligonucleotides 


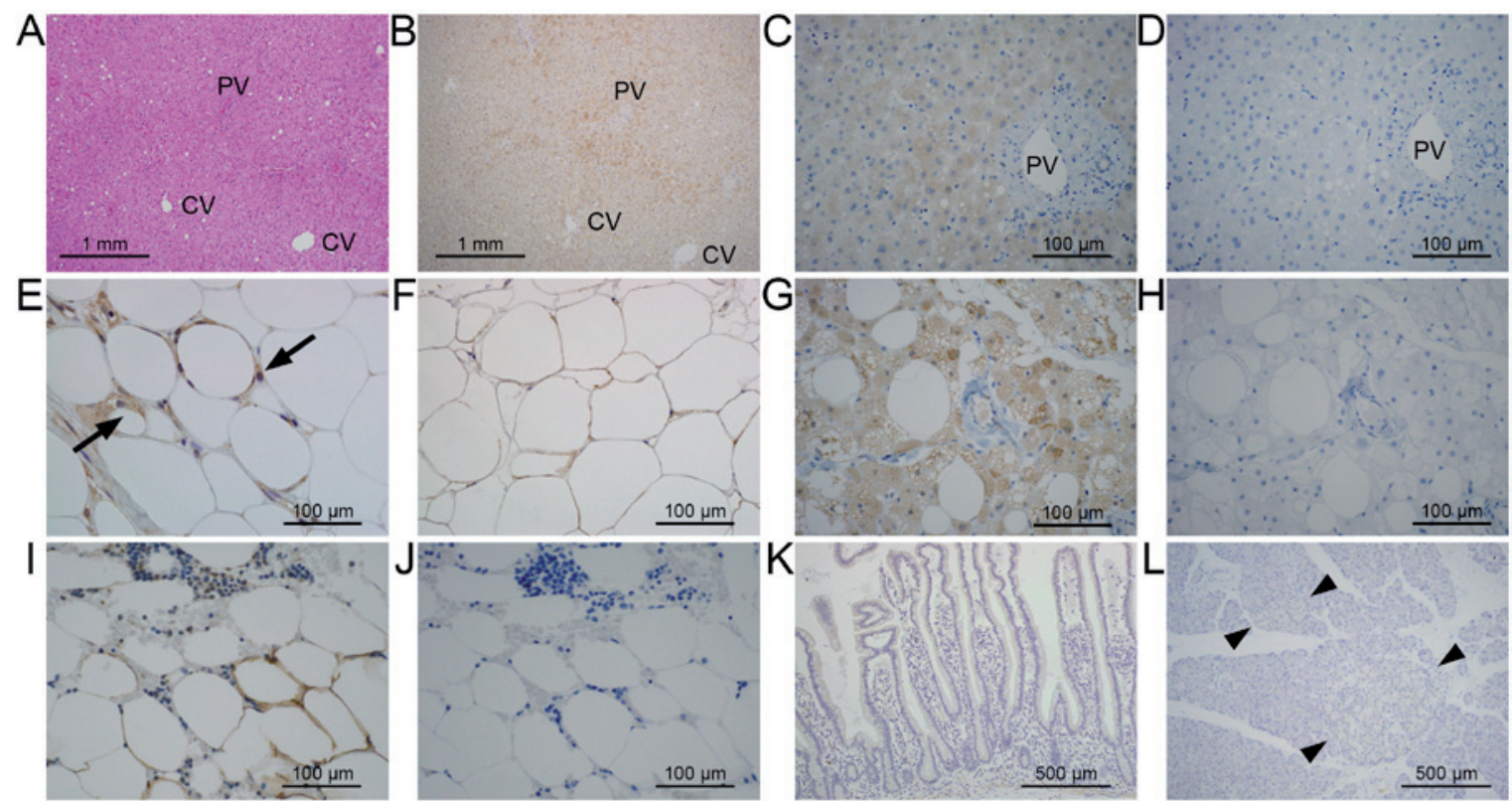

Figure 2. ANGPTL8 expression in human tissues by immunohistochemistry. (A) Hematoxylin \& eosin staining of liver tissues (magnification, x40). ANGPTL8 expression in portal hepatocytes (B) at magnification, $\mathrm{x} 40$ and (C) at higher magnification of the portal area (magnification, x200). (D) Negative control liver tissues without primary antibody (magnification, x200). (E) ANGPTL8 expression in the adipose tissue; positive staining of small immature adipocytes (arrows; magnification, x200). (F) ANGPTL8 expression in lipoma (magnification, x200). (G) ANGPTL8 expression in tumor cells in hibernoma (magnification, x200). (H) Negative control of hibernoma without primary antibody (magnification, x200). (I) ANGPTL8 expression in bone marrow (magnification, x200). (J) Negative control of the bone marrow without primary antibody (magnification, x200). ANGPTL8 expression in (K) the small intestine or (L) pancreatic islets (arrow heads; magnification, x100). ANGPTL8, angiopoietin-like protein 8; CV, central vein; PV, portal vein.
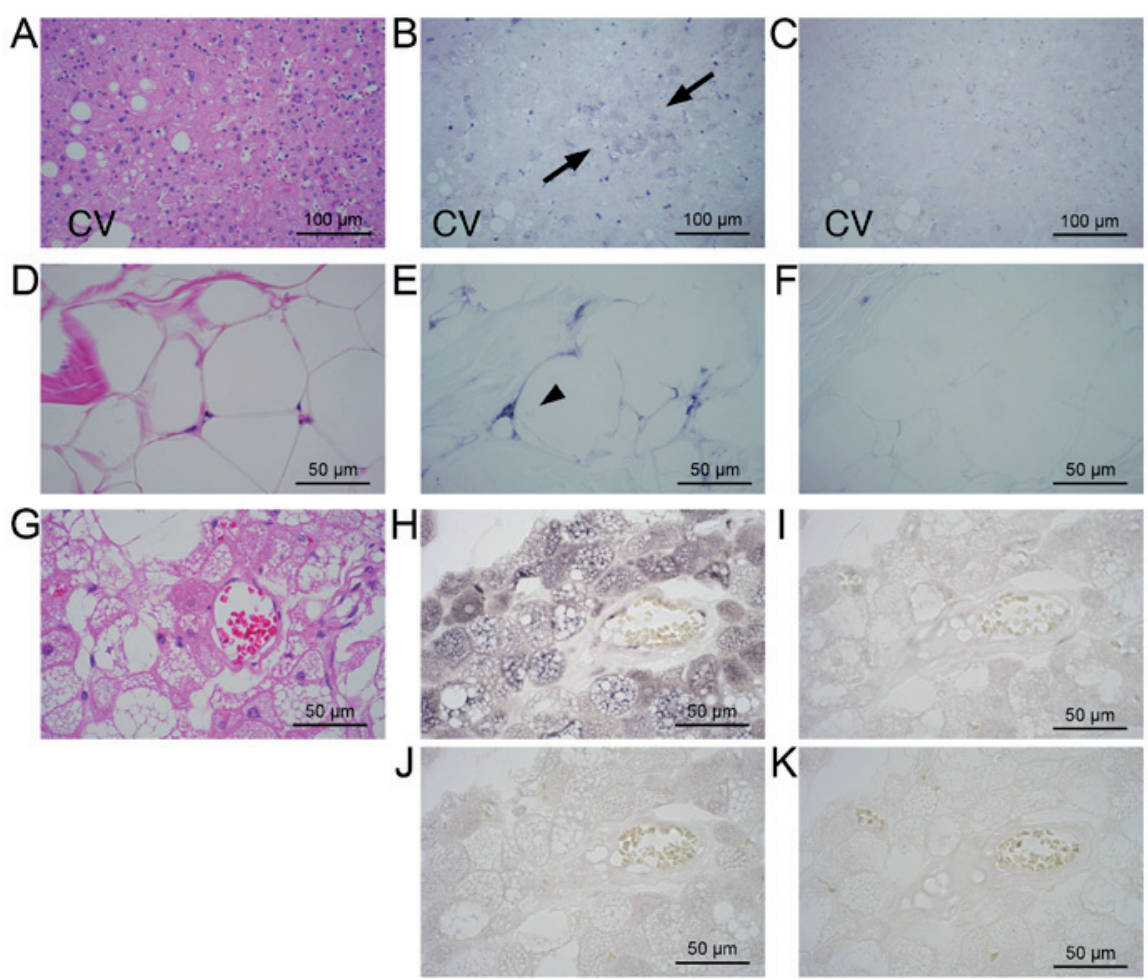

Figure 3. Wild type ANGPTL8 mRNA expression in human tissues by in situ hybridization. (A) Hematoxylin \& eosin staining of the liver. Staining of the liver with (B) the anti-sense probe (arrows, positively stained portal hepatocytes) and (C) the sense probe (magnification, x200). (D) Hematoxylin \& eosin staining of the adipose tissue. Staining of the lipoma with (E) the anti-sense probe (arrow head, small immature adipocytes) and (F) the sense probe (magnification, $\mathrm{x} 400$ ). (G) Hematoxylin \& eosin staining of hibernoma. Staining of hibernoma with (H) the anti-sense probe and (I) the sense probe. Staining of the sections treated with (J) RNase and hybridized with anti-sense probe or $(\mathrm{K})$ no probe (magnification, $\mathrm{x} 400$ ). ANGPTL8, angiopoietin-like protein 8; CV, central vein.

against ANGPTL8. Immature adipocytes release various metabolic factors, such as leptin and adiponectin (14), and the expression of enzymes associated with the lipid metabolism and leptin are upregulated in adipocytes with ANGPTL8 
knockdown (12). Therefore, it is conceivable that the prevention of steatosis and improvements in glucose metabolism was, in part, attributed to the modulation of metabolic factors by ANGPTL8 knockdown in immature adipocytes.

In the present study, we identified two splice variants of ANGPTL8 in the liver, which resulted in production of truncated forms of ANGPTL8 protein. These splice variants contain a conserved region of specific epitope 1, which is necessary for the inhibition of LPL. However, the coiled-coil domains, which are necessary for binding with ANGPTL3 $(15,16)$, were deleted. The inhibitory effect of LPL by ANGPTL8 requires complex formation with ANGPTL3 (17-19). ANGPTL8 further forms a complex with ANGPTL4, inactivating the inhibitory effect of ANGPTL4 on LPL (19). The almost complete deletion of C-terminal coiled-coil domains of ANGPTL8, like splice variant 1 , may loose the ability to form complex. The partial deletion of the C-terminal coiled-coil domain of ANGPTL8, like splice variant 2, may interfere the complex formation with ANGPTL3 and ANGPTL4 and affect the partitioning of lipids by modulating the inhibitory effect on LPL. Although the expression level of splice variant 2 was very low in the normal liver, the expression level of ANGPTL8 in metabolic and liver diseases needs to be elucidated.

The splice variants assessed in the present study contained two SNPs (rs1541922 and rs192460764). SNP rs192460764 caused the replacement of an amino acid (p.Arg172Trp). A previous study reported that another SNP rs2278426, causing the same replacement (p.Arg59Trp), is associated with ethnic and gender-specific differences in lipid levels in the Chinese population (20). The frequency of this SNP is high in patients with type 2 diabetes in Japan (21). The biological significance of SNPs of ANGPTL8 in lipid metabolism and metabolic diseases needs to be clarified.

An increase in serum levels of ANGPTL8 was reported in patients with type 1 and type 2 diabetes $(22,23)$, as well as gestational diabetes (24). It was reported that ANGPTL8 stimulates the proliferation of $\beta$-cells in the pancreatic islet (5); however, the biological activity is not reproduced $(25,26)$. The increase in ANGPTL8 in the serum is considered to be associated with lipid dysmetabolism in diabetes (27). A direct association between ANGPTL8 expression and $\beta$-cell proliferation was not evident in the present study.

The present study demonstrated high expression levels of ANGPTL8 and detailed the precise localization of the cells expressing ANGPTL8 in the liver and adipose tissue. The expression was associated with the activity of lipid metabolism and differentiation state in these organs. The modulation of metabolism and partitioning of triglyceride by the alteration of ANGPTL8 by anti-sense oligonucleotide may be a novel therapy for lipid dysmetabolism or steatohepatitis. The localization of ANGPTL8-expressing cells in the liver and adipose tissue may aid the understanding of partitioning of lipids and development of novel therapies targeting the lipid metabolism.

\section{Acknowledgements}

The authors would like to acknowledge the excellent assistance of Ms. Kiyoko Kawahara and Mr. Takenori Fujii for help with ISH, Mr. Kiyoshi Teduka and Ms. Yoko Kawamoto for help with IHC and Ms. Taeko Kitamura for help with the subcloning and RT-qPCR (Department of Integrated Diagnostic Pathology, Nippon Medical School, Tokyo, Japan).

\section{Funding}

No funding was received.

\section{Availability of data and materials}

All data generated or analyzed during this study are available from the corresponding author on reasonable request.

\section{Authors' contributions}

NA, RW and ZN designed the study and wrote the manuscript. NA performed histological examinations. NA and RW conducted biochemical examinations, data analyses and statistical analyses. NA prepared the figures and table. NA and KI provided clinical data of the patients and assisted with revising the manuscript. KI and ZN supervised the experimental design and manuscript writing. All authors read and approved the final manuscript. All authors agree to be accountable for all aspects of the work in ensuring that questions related to the accuracy or integrity of any part of the work are appropriately investigated and resolved.

\section{Ethics approval and consent to participate}

The study was approved by the Ethics Committee of the Nippon Medical School Hospital (Tokyo, Japan; approval no. 30-11-1304). Informed consent was obtained from all patients.

\section{Patient consent for publication}

Not applicable.

\section{Competing interests}

The authors declare that they have no competing interests.

\section{References}

1. Li Y and Teng C: Angiopoietin-like proteins 3, 4 and 8 regulating lipid metabolism and providing new hope for metabolic syndrome. J Drug Target 22: 679-687, 2014.

2. Ren G, Kim JY and Smas CM: Identification of RIFL, a novel adipocyte-enriched insulin target gene with a role in lipid metabolism. Am J Physiol Endocrinol Metab 303: E334-E351, 2012.

3. Dong XY, Pang XW, Yu ST, Su YR, Wang HC, Yin YH, Wang YD and Chen WF: Identification of genes differentially expressed in human hepatocellular carcinoma by a modified suppression subtractive hybridization method. Int J Cancer 112: 239-248, 2004.

4. Fu Z, Yao F, Abou-Samra AB and Zhang R: Lipasin, thermoregulated in brown fat, is a novel but atypical member of the angiopoietin-like protein family. Biochem Biophys Res Commun 430: 1126-1131, 2013

5. Yi P, Park JS and Melton DA: Betatrophin: a hormone that controls pancreatic $\beta$ cell proliferation. Cell 153: 747-758, 2013.

6. Quagliarini F, Wang Y, Kozlitina J, Grishin NV, Hyde R, Boerwinkle E, Valenzuela DM, Murphy AJ, Cohen JC and Hobbs HH: Atypical angiopoietin-like protein that regulates ANGPTL3. Proc Natl Acad Sci USA 109: 19751-19756, 2012. 
7. Wang Y, Quagliarini F, Gusarova V, Gromada J, Valenzuela DM, Cohen JC and Hobbs HH: Mice lacking ANGPTL8 (Betatrophin) manifest disrupted triglyceride metabolism without impaired glucose homeostasis. Proc Natl Acad Sci USA 110: 16109-16114, 2013.

8. Livak KJ and Schmittgen TD: Analysis of relative gene expression data using real-time quantitative PCR and the 2(-Delta Delta C(T)) method. Methods 25: 402-408, 2001.

9. Hijmans BS, Grefhorst A, Oosterveer MH and Groen AK: Zonation of glucose and fatty acid metabolism in the liver Mechanism and metabolic consequences. Biochimie 96: 121-129, 2014.

10. von Loeffelholz, Pfeiffer AFH, Lock JF, Lieske S, Docke S, Murahovschi V, Kriebel J, de Las Heras Gala, Grallert H, Rudovich N, et al: ANGPTL8 (Betatrophin) is expressed in visceral adipose tissue and relates to human hepatic steatosis in two independent clinical collectives. Horm Metab Res 49: 343-349, 2017.

11. Lee YH, Lee SG, Lee CJ, Kim SH, Song YM, Yoon MR, Jeon BH, Lee JH, Lee BW, Kang ES, et al: Association between betatrophin/ANGPTL8 and non-alcoholic fatty liver disease Animal and human studies. Sci Rep 6: 24013, 2016.

12. Mysore R, Liebisch G, Zhou Y, Olkkonen VM and Nidhina Haridas PA: Angiopoietin-like 8 (Angpt18) controls adipocyte lipolysis and phospholipid composition. Chem Phys Lipids 207: 246-252, 2017.

13. Vatner DF, Goedeke L, Camporez JG, Lyu K, Nasiri AR, Zhang D, Bhanot S, Murray SF, Still CD, Gerhard GS, et al: Angptl8 antisense oligonucleotide improves adipose lipid metabolism and prevents diet-induced NAFLD and hepatic insulin resistance in rodents. Diabetologia 61: 1435-1446, 2018.

14. Yu YH and Zhu H: Chronological changes in metabolism and functions of cultured adipocytes A hypothesis for cell aging in mature adipocytes. Am J Physiol Endocrinol Metab 286: E402-E410, 2004

15. Siddiqa A, Ahmad J, Ali A, Paracha RZ, Bibi Z and Aslam B Structural characterization of ANGPTL8 (betatrophin) with its interacting partner lipoprotein lipase. Comput Biol Chem 61: 210-220, 2016

16. Tseng YH, Yeh YH, Chen WJ and Lin KH: Emerging regulation and function of betatrophin. Int J Mol Sci 15: 23640-23657, 2014.

17. Haller JF, Mintah IJ, Shihanian LM, Stevis P, Buckler D, Alexa-Braun CA, Kleiner S, Banfi S, Cohen JC, Hobbs HH, et al: ANGPTL8 requires ANGPTL3 to inhibit lipoprotein lipase and plasma triglyceride clearance. J Lipid Res 58: 1166-1173, 2017.
18. Nidhina Haridas PA, Soronen J, Sadevirta S, Mysore R, Quagliarini F, Pasternack A, Metso J, Perttila J, Leivonen M, Smas CM, et al: Regulation of angiopoietin-like proteins (ANGPTLs) 3 and 8 by insulin. J Clin Endocrinol Metab 100: E1299-E1307, 2015.

19. Kovrov O, Kristensen KK, Larsson E, Ploug M and Olivecrona G: On the mechanism of angiopoietin-like protein 8 for control of lipoprotein lipase activity. J Lipid Res 60: 783-793, 2019.

20. Guo T, Yin RX, Wu J, Lin QZ, Shi GY, Shen SW, Sun JQ, Li H, Lin WX and Yan DZ: Association of the angiopoietin-like protein 8 rs2278426 polymorphism and several environmental factors with serum lipid levels. Mol Med Rep 12: 3285-3296, 2015.

21. Liu J, Yagi K, Nohara A, Chujo D, Ohbatake A, Fujimoto A, Miyamoto Y, Kobayashi J and Yamagishi M: High frequency of type 2 diabetes and impaired glucose tolerance in Japanese subjects with the angiopoietin-like protein $8 \mathrm{R} 59 \mathrm{~W}$ variant. J Clin Lipidol 12: 331-337, 2018.

22. Espes D, Lau J and Carlsson PO: Increased circulating levels of betatrophin in individuals with long-standing type 1 diabetes. Diabetologia 57: 50-53, 2014.

23. Hu H, Sun W, Yu S, Hong X, Qian W, Tang B, Wang D, Yang L, Wang J, Mao C, et al: Increased circulating levels of betatrophin in newly diagnosed type 2 diabetic patients. Diabetes Care 37: 2718-2722, 2014.

24. Ebert T, Kralisch S, Wurst U, Lössner U, Kratzsch J, Blüher M, Stumvoll M, Tönjes A and Fasshauer M: Betatrophin levels are increased in women with gestational diabetes mellitus compared to healthy pregnant controls. Eur J Endocrinol 173: 1-7, 2015.

25. Gusarova V, Alexa CA, Na E, Stevis PE, Xin Y, Bonner-Weir S, Cohen JC, Hobbs HH, Murphy AJ, Yancopoulos GD and Gromada J: ANGPTL8/betatrophin does not control pancreatic beta cell expansion. Cell 159: 691-696, 2014.

26. Yi P, Park JS and Melton DA: Retraction notice to Betatrophin A hormone that controls pancreatic $\beta$ cell proliferation. Cell 168 : 326, 2017.

27. Fenzl A, Itariu BK, Kosi L, Fritzer-Szekeres M,Kautzky-Willer A, Stulnig TM and Kiefer FW: Circulating betatrophin correlates with atherogenic lipid profiles but not with glucose and insulin levels in insulin-resistant individuals. Diabetologia 57: 1204-1208, 2014. 